\title{
Restoration of the catalytic activity of the surface and stabilization of the activating solution based on copper(I) before chemical copper plating
}

\author{
C Ludmila A. Brusnitsina, ${ }^{1,2} *^{+}$Elena I. Stepanovskih ${ }^{1}$, and Tatiana A. Alekseeva ${ }^{1}$ \\ ${ }^{1}$ Physical Chemistry and Chemistry of Colloids Academic Department. \\ Ural Federal University Named after the First President of Russia B.N. Yeltsin. \\ Mira St., 19. Yekaterinburg, 620002.Russia.E-mail: brusnitsyna.l@yandex.ru \\ ${ }^{2}$ Ural Institute of the State Fire Service of the Ministry of Emergency Measures of Russia. \\ Mira St., 22. Yekaterinburg, 620062. Russia.
}

\begin{abstract}
*Supervising author; ${ }^{+}$Corresponding author
Keywords: reduction of copper(I), catalytic activity, stabilization of activating solutions, chemical copper plating, printed circuits.
\end{abstract}

\begin{abstract}
Methods of chemical activation of the dielectric surface, in which metal-catalyst particles are formed on it as a result of chemical transformations, are more universal, since they allow to vary the compositions of solutions of chemical deposition of metal and to precipitate metals on substrates of different chemical nature with different morphology and surface structure. Noble metal compounds and colloidal solutions characterized by limited storage stability due to the coagulation process are mainly used for surface activation.

Palladium-free activation is used for metallization of the surface of unfolded dielectrics and metallization of through holes of printed circuit boards. As a dielectric material used inorganic materials (ceramics, polycore, various types of ceramics) and organic fiberglass with epoxiconazole adhesive layer.

The aim of this work is to improve the technology of activation of non-conductive surfaces by true solutions based on copper(I) by optimizing the composition of the activator.

It is shown that the drying temperature affects the composition of the activator layer. Activates the layer obtained by drying at $323-373 \mathrm{~K}$, is composed of $\mathrm{CuCl}_{2} \cdot 2 \mathrm{H}_{2} \mathrm{O}$ and $\mathrm{Cu}_{2} \mathrm{O}$. The optimum mode of drying an activating solution based on copper(I) $(\mathrm{T}=353-373 \mathrm{~K}, \tau=15-20$ minutes $)$.

The compounds formed during the drying of the activating solution based on copper monochloride do not have catalytic activity sufficient to initiate chemical and electrochemical metallization reactions. Therefore, it is necessary to carry out an additional operation-acceleration in solutions of reducing agents. Solutions of hydrazine chloride $\left(\mathrm{N}_{2} \mathrm{H}_{4} \cdot \mathrm{HCl}\right)$, sodium hypophosphite $\left(\mathrm{NaH}_{2} \mathrm{PO}_{4} \cdot \mathrm{H}_{2} \mathrm{O}\right)$, hydroxylammonium chloride $\left(\mathrm{NH}_{2} \mathrm{OH} \cdot \mathrm{HCl}\right)$, the concentration of which varied in the range $(0.1-0.5) \mathrm{mol} \cdot \mathrm{l}^{-1}$, as well as a solution of alkaline formaldehyde were taken as these solutions.

The technology of activator acceleration in a solution of the following composition: hydroxylammonium chloride $\left(\mathrm{NH}_{2} \mathrm{OH} \cdot \mathrm{HCl}\right)-0.5 \mathrm{~mol} \cdot \mathrm{l}^{-1} ; \mathrm{pH}=8-10 ; \mathrm{T}=298 \mathrm{~K}$, which allows to significantly increase the surface concentration of catalytically active centers on the dielectric surface.

In order to determine the durability and performance of the activating solution, the stability of the copper(I) - based solution was studied. The durability and performance of the activating solution is ensured by the presence of copper monochloride in it. This is possible if the solution will constantly undergo a reaction of reduction of divalent copper to a monovalent state. For this purpose, sodium hypophosphite in an amount of $0.5 \mathrm{~mol} \cdot \mathrm{l}^{-1}$ and metallic copper with a concentration of $30 \mathrm{~g} \cdot \mathrm{l}^{-1}$ were introduced into the activating solution as a reducing agent.

The optimal composition of the activating solution containing $\left(\mathrm{mol} \cdot \mathrm{l}^{-1}\right)$ : copper chloride $(\mathrm{I})-3.10$; hydrochloric acid -3.10 ; surfactant OP-10 - 0.01; metallic copper 0.47 was established.

Methods of regeneration of copper(I) concentration in activation solutions have been developed, which can significantly extend their service life.
\end{abstract}




\section{References}

[1] M. Salkauskas, A. Vaskelis. Chemical metallization of plastics. Leningrad: Chemistry. 1985. 144p. (russian)

[2] L.A. Brusnitsyna, T.A. Alekseeva, E.I. Stepanovskikh. Dynamics of palladium (II) and tin (II) concentration changes in the activating solution. LC. 2016. Vol.89. No.9. P.1121-1128. (russian)

[3] G.A. Kitaev, V.N. Sosnitsky, L.A. Brusnitsyna. Solution of restoration of catalytic activity of a surface of drawing of the printed circuit. LC. 1989. Vol.62. No.6. P.1378-1380. (russian) 